\title{
FASHION INDUSTRY PROFESSIONALS' VIEWPOINTS ON CREATIVITY AT WORK
}

\author{
Sigita BUKANTAITÉ (D), Živilė SEDEREVIČIŪTÉ-PAČIAUSKIENÉ (D) * \\ Department of Creative Communication, Faculty of Creative Industries, Vilnius Gediminas Technical \\ University, Traku str. 1, 01132, Vilnius, Lithuania
}

Received 22 September 2020; accepted 31 March 2021

\begin{abstract}
The article investigates the attitude of fashion industry managers towards creativity competence and its application in the fashion retail industry. The semi-structured interviews with middle managers allowed distinguishing three categories of activities. In the fashion retail industry, managers need creativity competence: performing technical assignments, working with clients, and working with staff members. For this research, middle managers were chosen because they are the mediators between the company's general managers and the sales-men. Middle managers play an essential role in bringing organization's culture, organizing sales-men's work, and personal development. Therefore, creativity is crucial for managers to have in mind, as the fashion industry is fast changing and dynamic. Creativity competence is effective in a team only if there is proper communication of a manager who can assure all team members understand the organization's primary purposes and values. The research revealed that managers apply various methods for promoting creativity that includes verbal interactions: discussions, delegating responsibility or tasks, sales promotion games, accumulation and systemization of information, sharing within social networks, provision of feedback, and encouragement of independent search for solutions. This study's results can help develop job descriptions that would attract the right employees to fashion sales. Understanding the importance of creativity in a salesperson's day-to-day work can help look at technical or repetitive work differently, increase sales staff's motivation, and improve sales results.
\end{abstract}

Keywords: communication, creativity, empowering leadership, fashion industry, fashion management, fashion retail, retail store management.

\section{Introduction}

Creativity is one of the most important qualities of a modern manager. Creativity itself is the abandonment of strict structures and some restrictions of thinking. Therefore, it is a very desirable trait for individuals in leadership positions to have in nowadays world. Creativity, innovation, and flexibility are essential skills in today's labor market.

Fashion industry is one of the areas that requires creativity in all the parts of value chain. With the growing popularity of contactless Internet trade, physical shops have retained one

${ }^{\star}$ Corresponding author. E-mail: zivile.sedereviciute-paciauskiene@vilniustech.lt

Copyright (c) 2021 The Author(s). Published by Vilnius Gediminas Technical University

This is an Open Access article distributed under the terms of the Creative Commons Attribution License (http://creativecommons. org/licenses/by/4.0/), which permits unrestricted use, distribution, and reproduction in any medium, provided the original author and source are credited. 
advantage, i.e., a possibility of live contact and establishing an emotional relationship between the client and the product. Due to this contact, considerable attention should be attributed to employees of physical points of sale, which meet clients, clarify and satisfy their needs. Today, organizations compete over crucial assets such as proficient and skilled employees. This poses a significant challenge to leaders as regards managing talented people (Stephens \& Carmeli, 2017). The immediate superior is responsible for employees' competence development in physical shops. Therefore, it is essential to clarify managers' attitude towards creativity at work and ways of its promotion.

This article aims to identify how the middle managers in fashion retail evaluate and encourage creativity. The research allowed comparing how fashion industry management's scientific approach and attitudes towards creativity comply and how the latter practically apply it in their work.

\title{
1. The discourse of creativity in fashion industry
}

Creativity is of utmost importance for fashion industry professionals (Karpova et al., 2011, 2013). According to Tracy Jennings, "creativity is the backbone of fashion design" (2011, p. 13). Researchers in various conceptions have broadly discussed the concept of creativity. One of the first written definitions of creativity brings us to ancient Greece, wherein 380 BC, Plato stated that creative people nurture improvement of society (2014). This Plato's idea about creativity offers two qualities. Firstly, creativity can be used working with society. Secondly, creativity is connected to social improvement (Lau, 2016).

Following the social approach, creativity embraces creating something new and useful considering social and cultural environment (Mayer, 2002). Jovilè Barevičiūtè singles out creativity and creativeness and defines them as interacting and interrelated but at the same time different concepts:

\begin{abstract}
"Creativity is connected with the psychological type of an individual, his/her emotional attitude of mind, orientation in certain unpredictable or specific situations or circumstances, finding solutions or making decisions under unexpectedly developing circumstances, etc. Creativeness is predetermined by the abilities, potential or talents that an individual possesses, i.e., ability to convincingly perform a role in the performance, expressively deliver a speech in front of the audience, properly master a singing or dancing technique, etc." (2014, pp. 20-21).
\end{abstract}

Creativity, which artists and geniuses have exclusively owned for many years, recently passed into the hands of the "creative class". Most people's cultural needs and aspirations are being supplied by the market as goods and services. Nicholas Garnham said:
"If one turns one is back on an analysis of that dominant cultural process, one cannot understand either the culture of our time or the challenges and opportunities which that dominant culture offers to public policymakers" (1987, pp. 24-25).

It has placed the economic and social benefits of creativity on the policy agenda (Garnham, 1990; Caves, 2000). Globalization has strengthened this process, which was initiated and supported by a general trend towards market liberalization and the withdrawal of the state as a dominant player in the economic life (Castells, 2000). Creativity has become an 
integral part of a neoliberal regime of governance, where the outcomes of broader networks of collaborative socialized production are positioned as the efforts of a professional creative class dedicated to entrepreneurial self-realization, and common symbolic resources are transformed into tradable property rights (Gershon, 2011). The concept of creative industries was trying to chart a historical shift from subsidized "public arts" and broadcast era media towards new and broader applications of creativity (Cunningham, 2002). Today, the creative industries form an important part of many urban economies, and the fashion industries are one of the exemplar creative industries.

Creativity in fashion industry is not necessarily characterized by novelty. Certain economy brands frequently create what has already been designed by the grand fashion houses only at affordable prices. This does not mean that they fail to create a useful product. Simply, this product is neither new nor original. The fashion industry aims at creating a product with a practical function. Therefore, the product has to address the client's needs in a subtle way, creating a harmony recognised by the client and allowing for simultaneous discovery of exceptional characteristics of this product (Ruppert-Stroescu \& Hawley, 2014). The process of globalization is understood as a large-scale socio-technical and organizational change process, was initiated and supported by a general trend towards market liberalization and the state's withdrawal as a dominant player in the economic life (Castells, 2000).

Creativity in fashion industry has an additional requirement - to create value (Csikszentmihalyi, 2013), simultaneously suggesting a desire and willingness to change (Kawamura, 2005; Wilson, 2013). Fashion industry would hardly be imaginable without this ambition because the people's wish to change creates usefulness of fashion industry, i.e., fashion satisfies the desire it generates.

Two types of creative products exist in the fashion industry. The leadership creativity (such products are innovative, high quality, ahead with fashion, produced in minimal quantities; meeting the high-quality standards, they appear to be an investment and their lifespan is long) manifests itself in designing and developing a product. The other creativity is adaptive and refers to products that reach shops. Although their appearance is very similar to that of leadership creativity products, the price of such products is lower, they are produced in considerably larger quantities and, thus, are affordable to a much more significant number of people. Due to their lower quality standard, their lifespan is relatively shorter (RuppertStroescu \& Hawley, 2014). These two categories in fashion make each other create because an increase in affordable products leads to a drop in demand for their primary products that are expensive and innovative. Thus, leadership creativity has to create new products, which should generate a desire of people to want them again. Such creativity is distinguished by originality, whereas adaptive creativity is characterized by its usefulness more because products are affordable and consumed.

The literature sources also provide two more kinds of creativity, which can be compared to leadership creativity and adaptive creativity, i.e., "Big-C" and "little-c" "Big-C" refers to eminent creativity, for example, such as Sigmund Freud's psychology or Emily Dickinson's poetry. On the other hand, "little-c" is everyday creativity, which is accessible to everyone (Stein, 1953). The researchers supplemented this division with two additional categories, "mini-c" and "pro-c". "Mini-c" creativity comprises individuals' personal learning experiences; these 
might be creative to the individual but not to others (Lassig, 2020). "Pro-c" fills in the gap between the "Big-C" and "little-c". The "pro-c" category representatives are professional artists who have not received or will never receive the title of prominent artists (Kaufman \& Sternberg, 2010). Similarly, there are many variants between the leadership creativity and adaptive creativity, e.g., not yet are recognized but highly significant local creators, whose products are original and innovative but at the same time, affordable to many people.

Florida (2019), dividing creative class into two main groups: super-creative core and creative professionals, suggests that science and business are areas in which one should be innovative and creative. Fashion industry needs innovations and creativity in every part of value chain, starting with one of the most important factors - time. In fashion industry, everything is planned, so the creators must see the future's needs, so that is why innovative thinking plays essential role. Fashion industry would not be imagined without famous brands. What makes them outstanding is their values, story, beliefs, design - all these things are mostly created on purpose and make customers fall in love with the brand and be loyal.

Fashion industry calls for a creative team in all the stages of fashion lifecycle, i.e., in product design and sales. Employees' creativity in the workplace is one of the key drivers of organizational innovation (Amabile et al., 1996; Ramalingam et al., 2015; Liu et al., 2017). According to the fashion professionals, a creative person is characterized by the following qualities: different thought processes, determination, an open mind, and risk-taking (Karpova et al., 2013).

Referring to creativity in a team, an informal influence, when team members have an impact on each other regardless of their position in the team, is a significant factor. The relation between informal influence hierarchy and team creativity is negative when the manager lacks empowering behavior. In other words, although hierarchy of informal influence has a positive impact on completion of assignments, particularly in case of complex assignments (Bunderson et al., 2016; Ronay et al., 2012), a team tends to be less creative when the leader fails to empower it, even though hierarchy of informal influence remains strong (Oedzes et al., 2018).

Effective teamwork as a key to success in fashion industry cannot be imagined without communication. To develop a plan or a working strategy, members of a team must engage in communication. Furthermore, exchanging information helps to understand competencies of all members, that is prior to empowering leadership. Scientists have proven that effectively gathering and exchanging information is important for team performance (e.g., Barry \& Stewart, 1997; Hyatt \& Ruddy, 1997). Boies et al. (2015) conclude that encouraging withinteam communication is a central mechanism through which transformational leaders might influence the formation of trust in teams and, ultimately, team performance. Leaders who express inspirational motivation are more likely to formulate a compelling vision of the future that will be a goal, toward which the team can work, so with the help of communication, a creative leader creates a goal-setting theory (e.g., Locke $\&$ Latham, 2002). Also, the inspiring leader makes the team more confident in competition and reflects their ability to succeed. Furthermore, the inspirationally motivating leader unites all employees showing the importance of working as a team. It can be said that inspiration of a leader is a powerful tool, which we would expect to lead to more excellent task performance. 
In order for organizations to pursue continuous innovation and success, managers need to create an environment conducive to renewal and create an organizational culture that encourages creativity and innovation (Agbor, 2008). Creativity and innovation are one of the most important conditions to survive in the competition between the organizations. According to Kačerauskas, "creativity destroys the status quo relationships both inside an organization (horizontal relationships) and outside it (vertical relationships)" (2016, p. 37). In fashion industry, the same strategies as in other areas are used for promotion of creativity: formal training, exposure to the world (developed creativity), practicing creative thinking and safe yet challenging environment (innate creativity) (Karpova et al., 2013).

Creativity is a significant condition in the areas like fashion industry. The assignments there are not strictly structured and empowering leadership is a relevant model of management. During their research, Lee et al. (2018) established that empowering leadership positively impacts organisational citizenship (voluntary commitment within an organization, which is not included in the work contract) and creativity at personal and team levels.

Empowering leadership develops personal efficacy eliminating bureaucratic restrictions and developing autonomy, delegating authority to employees, when they are allowed to approach their work as property, when employees are engaged in decision-making processes and able to get access to relevant information in the organisation. Empowering leadership style promotes employees' creativity (Zhang et al., 2018).

Empowering leadership has several advantages. Firstly, it can influence a wide variety of withdrawal behaviours (lateness, absenteeism, and turnover intentions). It does this at the individual level, and affective organizational commitment is another outcome of correct empowering leadership. Kim and Beehr (2020) point out that empowering leadership has motivational influences on followers by promoting their sense of control, confidence in their jobs, and feelings of being empowered, conferring greater authority and autonomy.

A lot of business literature sources have focused on fostering creativity in general and therefore researchers lack an attentive understanding of its impact on employees' attitudes and behaviours in fashion industry that encourage creativity of the team of a retail store. Employee creativity is a particularly fundamental organizational aspect (Li-Ping Tang, 2010).

The research aimed to analyze how managers of different levels working in the fashion retail industry evaluate and encourage creativity.

\section{The research methods}

Employing a semi-structured interview, the research was conducted in one of the largest joint-stock retailer companies in Lithuania, from 19 March - 19 April, 2020. This company was chosen because of a large number of outlets all over Lithuania and the variety of segments (luxury, youth, economy and business classes). The company's name is not mentioned in the article for ethical reasons, as agreed before the investigation.

Semi-structured interviews with middle managers were carried out and non-probabilistic convenience sampling was used for the data collection (Yin, 2013; Etikan et al., 2016). The data saturation element was used to determine the size of the sample. The interviews were terminated after information saturation was reached (Fusch \& Ness, 2015; Malterud et al., 
2016). Twelve managers working in subsidiaries located in different Lithuanian cities (Vilnius, Kaunas, Klaipeda) and in different segments (luxury, youth, economy and business classes) as well as three functional managers (training, human resources and sales) were interviewed. The interviews were carried out online because of quarantine restrictions. The questions were sent to the personal e-mails of the managers, who had expressed their consent to participate in the research. The detailed notes from calls that followed the completed survey were added to the transcripts (DeWeese et al., 2017; Salmons, 2017). All unique identifiers (e.g., names of people or places) were removed from the transcripts, and none were included in manuscript (DeWeese et al., 2017). The inductive content analysis was accomplished reading through the transcripts, adding marginal notes and assigning preliminary codes. The themes, and patterns within and among these themes where identified (Elo \& Kyngäs, 2008; Moser \& Korstjens, 2018). The content analysis approach was applied to analyze the data (Elo \& Kyngäs, 2008) and variation-based generalization was used to describe the findings (Quinn Patton, 1990; Smaling, 2003).

\section{The research results}

The analysis of informants' responses about application of creativity in work-related situations highlighted three main spheres of creativity application: technical assignments (finding more new efficient ways of task completion or behaving in new situations, presentation/ arrangement of goods in the sales areas, storing and other routine tasks, completion of monotonous assignments), work with clients (creating matching sets for clients, selling, addressing unpleasant situations with clients) and work with staff (mobilization for attainment of goals; team members are more interested in a product/result, when information is presented creatively, it helps to engage new staff members and evoke their interest in work; employees are not indifferent to assignments; a team puts forwards ideas with courage, helps to create a good atmosphere in the workplace). The informants pointed out that creativity contributes to improved technical assignments, work with clients, and staff members. This can be regarded as the main categories of assignments, where creativity is a contributory factor (Table 1). It is important for the manager to treat these three work areas as creative once and communicate properly to employees about how much creative freedom employees have. This could help employees to see more meaning in their work and be more motivated.

It is interesting that although the majority of informants stated that they apply creativity while completing tasks in the sales areas, communicating with clients or working with their team, responding to the question about the creative process, they pointed out that they allocate only $40 \%$ of their working time to it. Such situation may be predetermined by the fact that the informants perceive a creative process as working time that is dedicated to searching for the solution to a problem or devising a plan. The remaining time is assigned to implementation and, that is why, does not require creativity. For example, the informant stated that he allocates only $5 \%$ of his working time to the creative process. When he was asked about how he encourages creativity and innovations in his team, he explained that every week for about 30 minutes his deputy and he discusses how to improve processes, share thoughts and observations, meetings are also dedicated to that. This means that problem solutions are 
Table 1. The activities in fashion retail industry, which require creativity (source: created by authors)

\begin{tabular}{|c|c|}
\hline Technical works & $\begin{array}{l}\text { "[...] discovering new ways of productive performing of works or } \\
\text { behaving in new situations". } \\
\text { "Presentation of goods in the shop - solutions are faster found, } \\
\text { when a product of complicated integration is to be presented". } \\
\text { "[...] storage and other daily chores". } \\
\text { "[...] to perform monotonous assignments". }\end{array}$ \\
\hline Work with clients & $\begin{array}{l}\text { "[..] while creating matching sets of clothes for clients or in sales". } \\
\text { "[...] in unpleasant situations with clients". }\end{array}$ \\
\hline Work with staff & $\begin{array}{l}\text { "[...] mobilizes for pursuance of goals". } \\
\text { "The team is very interested in the results/the product, when } \\
\text { information is provided creatively". } \\
\text { "[...] helps to engage young people in work and to enhance their } \\
\text { interest in it". } \\
\text { "[...] employees are not indifferent to assignments". } \\
\text { "[...] staff members suggest their ideas freely and with courage". } \\
\text { "[...] helps to create a good atmosphere in the workplace". }\end{array}$ \\
\hline
\end{tabular}

found while discussing, whereas other actions, without which implementation of decisions would not be possible, e.g., creative thinking before discussion, organisation of discussion, preparation, presentation of decision to the team, are not seen as a creative process.

The informants, who stated that they dedicate $80 \%$ of all their work to the creative process, pointed out that creativity in their work is needed in the following activities: presentation/demonstration of goods in the sales area (visual merchandising), client service (creation of image), problem-solving in the workplace, self-expression of staff members (responsibilities, new goals, improvement), dealing with innovations at work, motivating a team, improving hard indicators of shops and in technical assignments to make them more interesting. Such statements show that their authors do not necessarily involve in additional creative activities at work, but they link creativity with the majority of daily processes, which occur in the shop and attempt to make them more attractive. This means that creativity does not require additional time costs but is a part of daily assignments. However, the differences in understanding the concept of creativity are also observed and this predetermines the attitude of informants towards their work: some of them see their job more creative, whereas others find it less creative.

Aiming to clarify the attitude of informants towards creativity and its understanding, they were requested to comment on the idea of Plato (2014): "creative individuals nurture improvement of society". The informants supported this idea because "creativity is linked to generation of ideas and their testing, which naturally pushes society forward", "without creativity the society would not improve, we would not have as many discoveries and things that make our life easier as now", "the market requires changes and very fast, therefore employing own creativity, we can improve together". One informant only partially supported Plato's idea: "If we defined creativity as creation of new and unique ideas, I could not agree more with the presented ideas. On the other hand, it would be too brave to claim that all the new ideas a priori are good and have only a positive impact on society". The informants linked improvement of society with various technologies and innovations, which would not 
be available without creative people: "I think that thanks to ambitions of creative people, we are able to work or do shopping from home now or to complete an assignment at work at one click", "[...] creative solutions have changed our lifestyle. I think, today we can improve as fast as never before. Even such a thing as distance courses - you get an opportunity to learn from best online".

The informants stated that creative people nurture improvement of society on the basis of their personal improvement driven by creativity and all this contributes to development of society and problem solving as well because "[...] creative solutions help people to extend their limits especially if they are 'stuck' and immovable. Creativity reminds people of the fact that nothing stands still and helps to solve the most complicated situations". Other responses were also related to creativity as self-expression and generation of new ideas.

The informants were asked how they promote (if they do) creativity and innovations in their team. The ways of creativity promotion that were indicated by the informants can be divided into the following action categories: discussions, delegating responsibilities or assignments, sales promotion games, accumulation and systemization of information, sharing information with colleagues in social media, feedback, encouragement of independent search for solutions.

The informants distinguished discussions as a way to encourage creativity in their team: "I emphasize the importance of every team member and that every member can share insights and news that are useful to the team. They feel confidence and this encourages them to be creative". Managers emphasize free sharing of ideas and collective decision-making: "Firstly, everybody knows that we can freely exchange ideas, put forward new ones and nobody is 'suppressed"; "During the meeting together with the team we try to discuss the complicated areas and try to think of decisions how to improve them". Referring to promotion of creativity, the informants emphasized personal conversations and motivation of employees to move forward: "A mistake in our environment is seen as an opportunity to learn and move forward, therefore employees are not afraid to make mistakes and they generate a lot of new ideas"; "Frequently, together with a person, who is in charge of the team (the deputy), we discuss how to achieve better results [...] we think what can we do better, we share thoughts and observations".

The managers use delegation of responsibility or assignments as one of the ways that promote creativity: "In my shop everybody is responsible for a certain area (e.g. bags, women's shoes, men's shoes, accessories) and their goal is not only to ensure appropriate arrangement of goods but also achievement of the main general results of the shop. They are provided with guidelines but in fact they can do what they want [...]. The main aim is to make them feel that they possess a shop they are 100\% responsible for", "[...] the list of tasks that have to be completed within a week or in the nearest time is posted in a visible place in the warehouse, I delegate more complex and responsible assignments to responsible employees or to the ones who are learning according to the guidelines 'Try the profession on' and are pursuing a career". Delegating assignments managers seek to provide more responsibilities to the employees themselves, which, according to the former, is a way to promote their creativity: "I usually recommend my employees to choose more simple tasks themselves, to decide who wants to do what, to share equally in order to feel a part of team. And I frequently get requests to give more work and in such cases I tend to assign more responsibility to them". 
According to the informants, sales promotion games is one more way to employ creativity competence aiming at better results: "We play various games that promote sales. I also motivate them to think of ways how to improve the shop's results and this encourages creativity as well".

The informants distinguish accumulation and sharing of professional information as one more way of promoting creativity in own team: "We also encourage creativity while preparing A Product Knowledge Book, where information about available goods, how to match them, etc. is presented. This also helps us to become more creative and professional in the process of service". Gamification is mentioned as a way that increases the diversity of activities: "I suggest certain ideas, which they develop further and discover ways how to use them in practice. For example, a foreign language glossary, phrases or words most frequently used at work, a mini catalog with names of footwear and pictures, etc.".

Sharing of theoretical knowledge with colleagues in social networks is also one of the ways to promote creativity, which is pointed out by the informants: "Social networks help to share information creatively, to use various formats and all this stimulates creative thinking as well as creativity in the very team".

Provision of feedback was referred to as an important factor, which stimulates employees' creativity: "I always try to provide 'feedback' to my employees because it is important not to make them feel unappreciated or unnoticed" or "I sincerely believe in their ideas and support them. If I see a risk, I share my knowledge and then give my team members to decide themselves if they want to try one or another thing".

The informants stated that they encourage employees to make decisions independently and to be creative: "Firstly, I encourage person's initiative not to be afraid to think for themselves, I urge them to search for solutions independently instead of giving directions. I think that creativity and suggestion of new ideas derive from the individual's initiative, his/her sense of freedom".

Seeking to comprehensively clarify the informants' attitude towards creativity, they were presented with the statement that creativity is creation of an original and useful product, which was formulated by Mayer (2002) after he generalised the definitions of creativity suggested by seven authors. The informants commented on this thought questioning all the three elements and as if stating that creativity can exist without usefulness, originality and even doubting the creation of product. Usefulness, as a non-binding element of creativity, was defined in the following way: "I don't think that creativity can always be useful. Employing creativity one can create many things, which may not necessarily contain any usefulness in themselves and even, on the contrary, may be harmful. The Internet is full of things, which were created without any added value just for the sake of fun". Originality, according to the informants, is not always necessary defining creativity: "[...] we can discuss what is original today. How can we know that nobody has though of our idea before and that it is absolutely new and original? We read so much information, study certain areas and implement certain decisions. It is difficult to evaluate the extent to which they are original and not influenced by other recommendations, the read literature, etc.". The informants shared their considerations about whether creativity is necessarily finalised with development of a product: "[...] creativity is not only the final outcome but also the very process, which introduces experience and 
teaches something new". "[...] how to define usefulness? What do we refer to as a product? Somewhere in New York the flash mob gained the popularity. This idea really contains originality, a specific organised flash mob draws attention to a certain group or theme. It can also be perceived as useful, but can this action be defined as a product? I think that there are many more of such manifestations of creativity, which can hardly fit into the definition of product".

The informants, who agreed with the presented statement, pointed out that creativity brings advantage against competitors, it is useful and has to be original. They also referred to the examples of technological discoveries: "Would we have smart phones without creativity? Would there be a fashion industry? Would we have so many works of music or theatre? And we could ask lots of such questions. The answer is one - of course, not".

The informants stated that client service and presentation of goods can be seen as the product they create: "Creativity firstly depends on the ability to evoke the client's interest. To show something new and unexpected to him or her. The latter goal has not been attained yet but with the help of creativity we are moving towards it". Creativity of this type is easily visible because it has a physical expression and this is emphasised by all the managers: "With the help of creativity we give a tangible form to a product. We create an overall image for our clients [...], matching clothes, dressing manikins in the shop, as the received collection clothes are not presented separately but as a whole". "Our product is sold in the shop if there are other matching things nearby. [...] this is how we create a product". According to the informants, positive atmosphere also can be perceived as a created product: "Well, I don't create a tangible product [...], but I think that a friendly and united team can also be called a fruit of creativity".

The informants think that the product in their work is hardly measurable: "Since I work in the human resources, the final goal and the result are also hardly measurable in most cases. I can give an example of organised trainings. Creative ideas and decisions are linked really closely to creation and choice of training content. Therefore, it can be said that creation of content of training, as a product, is closely connected to creativity. However, if the final goal is conveyance of certain knowledge, creativity also remains important here but it does not fully fit into the concept of product".

Thus, visually seen but hardly measurable creativity in the fashion industry is creation of original and useful product but referring to promotion of creativity, the managers mainly distinguish common activities that aim at improvement of work processes.

\section{Discussion}

Creativity appears in personal entrepreneurial intention through mediating processes and mechanisms. As creativity and proactive personality are crucial components of the entrepreneurial process, it is also essential to develop creativity as well as others positive personality traits to stay successful in business (Hu et al., 2018).

Creativity is significant in fashion industry and is an important factor in all the parts of value creation chain (from an idea and creation of product to the contact with the client and sales). 
The managers working in fashion retail industry need creativity competence while performing technical assignments, dealing with clients and working with staff members. The surveyed managers use various ways of promoting employees' creativity: discussions, delegating responsibilities or tasks to subordinates, using sales promotion games, cumulating information and sharing it, employing social networks, providing feedback and encouraging independent use of solutions. The informants pointed out that team building and employees' support are some of the main processes, where creativity plays an important role. In their explorative study on the dialogue between individual and collective creativity in the fashion industry Cortini et al. (2019) summed up the results: it is possible to state that, according to the participants, the creative process is mostly individual. Some participants also consider the collaboration, but the majority described the team's role as support in terms of empathy or affection; indeed, a stylist defined the team "as a family", giving relevant importance to the human factor. Our research confirms that in some stages of value creation, creativity is individual but the managers indicated that they use delegation of responsibilities as one of the main ways to promote creativity. The team's creativity depends on different factors, but team empowerment is one of the most important ones. Empowering leadership is closely interrelated with creativity. The researchers state that creative teams work most successfully when they have autonomy and possibility of making decisions (Ryan \& Deci, 2000). The research results showed that joint decision making, increase of engagement, provision of employees to perform an assignment in their own way - they are the ways for expressing individual creativity in the team.

Although the works, where informants employ their creativity, occupy the more significant proportion of daily management work, the informants mentioned that they allocate only $40 \%$ of their working time to the creative process. All the informants easily identified the need for creativity, they also stated that they encouraged creativity of their employees and indicated the ways, how they do it. However, a significant proportion of their working time is left for performing the functions, where managers do not see any creativity. Therefore, managers should emphasize creative moments at work when communicating with the team and draw employees' attention to specific functions, naming them as creative. This can give employees more self-confidence and motivation at work. Managers need to communicate the importance of creativity in their work and identify where creativity is needed.

Middle managers seem to understand creativity as a tool to their everyday work rather than the purpose. If the middle managers most of the working time perform functional work, which is not creative, it is the question for a company - is the potential of the middle managers' fully exploited? This raises another question - if the managers are recruited accordingly to their creative competencies, does the company develop these competencies enough? It can be said that middle managers are focused on results and prioritize its efficiency. Therefore, creativity and its development become a secondary task and often stays outside the scope of attention.

This study's results can help develop job descriptions that would attract the right employees to fashion sales. Understanding the importance of creativity in a salesperson's day-to-day work can help look at technical or repetitive work differently, increase sales staff's motivation, and improve sales results. 


\section{Conclusions}

Fashion industry contains many different parts of value chain - from creating clothes and manufacturing them to merchandising in stores and marketing them. Fashion retail is very dynamic, the more and more market is taken by online shopping, leaving physical stores with a complex challenge to survive and attract customers. Therefore, it is important to develop a creative atmosphere in a workplace, to teach and motivate sales assistants as they directly interact with customers. Taking this responsibility into consideration middle managers are essential in fashion retail.

The fashion retail industry managers need creativity competence while performing technical assignments, dealing with clients, and working with staff members. The surveyed managers use various ways of promoting employees' creativity: discussions, delegating responsibilities or tasks to subordinates, using sales promotion games, cumulating information and sharing it, employing social networks, providing feedback and encouraging independent use of solutions. This shows that middle managers use empowering leadership in their everyday work. Empowering employees encourages them to be creative in solving problems and acting independently. In this way, company can benefit - employees are more engaged, when they feel the autonomy and can make some decisions by themselves.

The theme of creativity in fashion retail is highly relevant, although it has not been extensively analysed by the researchers. Research on fashion retail usually embraces processes but creative solutions while communicating with clients, encouragement of consultant creativity and its influence on sales success have been under-researched so far. This could be directions for further research. Further research could analyze how creativity and creative skills can be applied in management processes: planning fashion product marketing (forming a range, making pricing decisions, organizing the presentation and sponsorship of fashion products), and creating branding and marketing of individual fashion designers.

\section{References}

Agbor, E. (2008). Creativity and innovation: the leadership dynamics. Journal of Strategic Leadership, $1(1), 39-45$.

Amabile, T. M., Conti, R., Coon, H., Lazenby, J., \& Herron, M. (1996). Assessing the work environment for creativity. Academy of Management Journal, 39(5), 1154-1184. https://doi.org/10.2307/256995

Barevičiūtè, J. (2014). Pagrindiniai kūrybiškumo ir kūrybingumo aspektai šiuolaikiniuose humanitariniuose bei socialiniuose moksluose. Filosofija. Sociologija, 25(1), 19-28.

Barry, B., \& Stewart, G. L. (1997). Composition, process, and performance in self-managed groups: the role of personality. Journal of Applied Psychology, 82(1), 62-78.

https://doi.org/10.1037/0021-9010.82.1.62

Boies, K., Fiset, J., \& Gill, H. (2015). Communication and trust are key: unlocking the relationship between leadership and team performance and creativity. The Leadership Quarterly, 26(6), 1080-1094. https://doi.org/10.1016/j.leaqua.2015.07.007

Bunderson, J. S., Vegt, van der G. S., Cantimur, Y., \& Rink, F. (2016). Different views of hierarchy and why they matter: hierarchy as inequality or as cascading influence. Academy of Management Journal, 59(4), 1265-1289. https://doi.org/10.5465/amj.2014.0601 
Castells, M. (2000). The information age: economy, society and culture. Vol. 1: The rise of the network society. Wiley-Blackwell.

Caves, R. E. (2000). Creative industries: contracts between art and commerce. Harvard University Press.

Cortini, M., Colleluori, A., Marzini, R., Di Fiore, T., \& Fantinelli, S. (2019). Creativity between individual insight and group support: an explorative study in the Italian fashion industry. Studies in Psychology, 40(3), 635-663. https://doi.org/10.1080/02109395.2019.1660059

Csikszentmihalyi, M. (2013). Creativity: the psychology of discovery and invention. Harper Perennial/ Modern Classics.

Cunningham, S. (2002). From cultural to creative industries: theory, industry and policy implications. Media International Australia, 102(1), 54-65. https://doi.org/10.1177/1329878X0210200107

DeWeese, A. R., Jennings, P. A., Brown, J. L., Doyle, S. L., Davis, R. T., Rasheed, D. S., Frank, J. L., \& Greenberg, M. T. (2017). Coding semistructured interviews: examining coaching calls within the CARE for teachers program. SAGE Research Methods Cases, 2, 9-15. https://doi.org/10.4135/9781473958319

Elo, S., \& Kyngäs, H. (2008). The qualitative content analysis process. Journal of Advanced Nursing, 62(1), 107-115. https://doi.org/10.1111/j.1365-2648.2007.04569.x

Etikan, I., Abubakar Musa, S., \& Sunusi Alkassim, R. (2016). Comparison of convenience sampling and purposive sampling. American Journal of Theoretical and Applied Statistics, 5(1), 1-4. https://doi.org/10.11648/j.ajtas.20160501.11

Florida, R. (2019). The rise of the creative class. Hachette Book Group.

Fusch, P. I., \& Ness, L. R. (2015). Are we there yet? Data saturation in qualitative research. The Qualitative Report, 20(9), 1408-1416. https://doi.org/10.46743/2160-3715/2015.2281

Garnham, N. (1990). Capitalism and communication: global culture and the economics of information. SAGE Publications.

Garnham, N. (1987). Concepts of culture: public policy and the cultural industries. Cultural Studies, 1(1), 23-37. https://doi.org/10.1080/09502388700490021

Gershon, I. (2011). "Neoliberal agency”. Current Anthropology, 52(4), 537-555. https://doi.org/10.1086/660866

$\mathrm{Hu}, \mathrm{R}$., Wang, L., Zhang, W., \& Bin, P. (2018). Creativity, proactive personality, and entrepreneurial intention: the role of entrepreneurial alertness. Frontiers in Psychology, 9. https://doi.org/10.3389/fpsyg.2018.00951

Hyatt, D. E., \& Ruddy, Th. M. (1997). An examination of the relationship between work group characteristics and performance: once more into the breech. Personnel Psychology, 50(3), 553-585. https://doi.org/10.1111/j.1744-6570.1997.tb00703.x

Jennings, T. (2011). Creativity in fashion design: an inspiration workbook. Fairchild Books.

Kačerauskas, T. (2016). The paradoxes of creativity management. Business Administration and Management, 19(4), 33-43. https://doi.org/10.15240/tul/001/2016-4-003

Karpova, E., Marcketti, S., \& Barker, J. (2011). Putting the puzzle together: apparel professionals' perspectives on creativity. International Journal of Fashion Design, Technology and Education, 4(2), 103-113. https://doi.org/10.1080/17543266.2010.542185

Karpova, E., Marcketti, S., \& Kamm, C. (2013). Fashion industry professionals' viewpoints on creative traits and, strategies for creativity development. Thinking Skills and Creativity, 10, 159-167. https://doi.org/10.1016/j.tsc.2013.09.001

Kaufman, J. C., \& Sternberg, R. J. (Eds.). (2010). The Cambridge handbook of creativity. Cambridge University Press. https://doi.org/10.1017/CBO9780511763205

Kawamura, Y. (2005). Fashion-ology: an introduction to fashion studies. Berg Publishers. https://doi.org/10.2752/9781847888730 
Kim, M., \& Beehr, T. A. (2020). Empowering leadership: leading people to be present through affective organizational commitment? The International Journal of Human Resource Management, 31(16), 2017-2044. https://doi.org/10.1080/09585192.2018.1424017

Lassig, C. (2020). A typology of student creativity: creative personal expression, boundary pushing and task achievement. Thinking Skills and Creativity, 36. https://doi.org/10.1016/j.tsc.2020.100654

Lau, K. W. (2016). Understanding creativity competency for organizational learning: a study of employees' assumptions on creativity, competency in creative industry. Journal of Management Development, 35(10), 1198-1218. https://doi.org/10.1108/JMD-12-2015-0174

Lee, A., Willis, S., \& Wei Tian, A. (2018). Empowering leadership: a meta-analytic examination of incremental contribution, mediation, and moderation. Journal of Organizational Behavior, 39(3), 306-325. https://doi.org/10.1002/job.2220

Li-Ping Tang, Th. (2010). From increasing gas efficiency to enhancing creativity: it pays to go green. Journal of Business Ethics, 94, 149-155. https://doi.org/10.1007/s10551-009-0261-3

Liu, D., Gong, Y., Zhou, J., \& Huang, J.-Ch. (2017). Human resource systems, employee creativity, and firm innovation: the moderating role of firm ownership. Academy of Management Journal, 60(3), 1164-1188. https://doi.org/10.5465/amj.2015.0230

Locke, E. A., \& Latham, G. P. (2002). Building a practically useful theory of goal setting and task motivation: A 35-year odyssey. American Psychologist, 57(9), 705-717. https://doi.org/10.1037/0003-066X.57.9.705

Malterud, K., Siersma, V. D., \& Guassora, A. D. (2016). Sample size in qualitative interview studies: guided by information power. Qualitative Health Research, 26(13), 1753-1760. https://doi.org/10.1177/1049732315617444

Mayer, R. E. (2002). Fifty years of creativity research. In R. J. Sternberg (Ed.), Handbook of creativity (pp. 449-460). Cambridge University Press. https://doi.org/10.1017/CBO9780511807916.024

Moser, A., \& Korstjens, I. (2018). Series: Practical Guidance to Qualitative Research. Part 3: Sampling, data collection and analysis. European Journal of General Practice, 24(1), 9-18. https://doi.org/10.1080/13814788.2017.1375091

Oedzes, J. J., Rink, F. A., Walter, F., \& Vegt, van der G. S. (2018). Informal hierarchy and team creativity: the moderating role of empowering leadership. Applied Psychology, 68(1), 3-25. https://doi.org/10.1111/apps.12155

Plato. (2014). The Republic. Black \& White Classics.

Quinn Patton, M. (1990). Qualitative evaluation and research methods. SAGE Publications, Inc.

Ramalingam, Th., Abdul Karim, J., Piaralal, Sh., \& Singh, B. (2015). Creativity and innovation (organizational factor) influence on firm performance: an empirical study on Malaysian telecommunication mobile network operators. American Journal of Economics, 5(2), 194-199.

Ronay, R., Greenaway, K., Anicich, E. M., \& Galinsky, A. D. (2012). The path to glory is paved with hierarchy: when hierarchical differentiation increases group effectiveness. Psychological Science, 23(6), 669-677. https://doi.org/10.1177/0956797611433876

Ruppert-Stroescu, M., \& Hawley, J. M. (2014). A typology of creativity in fashion design and development. Fashion Practice: The Journal of Design, Creative Process and the Fashion Industry, 6(1), 9-35. https://doi.org/10.2752/175693814X13916967094759

Ryan, R. M., \& Deci, E. L. (2000). Self-determination theory and the facilitation of intrinsic motivation, social development, and well-being. American Psychologist, 55(1), 68-78. https://doi.org/10.1037/0003-066X.55.1.68

Salmons, J. (2017). Using social media in data collection: designing studies with the qualitative eresearch framework. In L. Sloan \& A. Quan-Haase (Eds.), The SAGE handbook of social media research methods (pp. 177-197). SAGE Publications Ltd. https://doi.org/10.4135/9781473983847.n12 
Smaling, A. (2003). Inductive, analogical, and communicative generalization. International Journal of Qualitative Methods, 2(1), 52-67. https://doi.org/10.1177/160940690300200105

Stein, M. I. (1953). Creativity and culture. The Journal of Psychology, 36(2), 311-322. https://doi.org/10.1080/00223980.1953.9712897

Stephens, J. P., \& Carmeli, A. (2017). Relational leadership and creativity: the effects of respectful engagement and caring on meaningfulness and creative work involvement. In M. D. Mumford \& D. Hemlin (Eds.), Handbook of research on leadership and creativity (pp. 273-296). Edward Elgar Publishing Limited. https://doi.org/10.4337/9781784715465.00021

Wilson, E. (2013). Adorned in dreams: fashion and modernity. I.B. Tauris.

Yin, R. K. (2013). Case study research: design and methods. SAGE Publications Inc.

Zhang, Sh., Ke, X., Wang, X.-H. F., \& Liu, J. (2018). Empowering leadership and employee creativity: a dual-mechanism perspective. Journal of Occupational and Organizational Psychology, 91(4), 896-917. https://doi.org/10.1111/joop.12219 